\title{
A high-frequency analysis of price resolution and pricing barriers in equities on the adoption of a new currency
}

\author{
Christos Alexakis*1, Mark Cummins ${ }^{2}$, Michael Dowling ${ }^{1}$ and Vasileios Pappas ${ }^{3}$ \\ ${ }^{1}$ Rennes School of Business \\ ${ }^{2}$ DCU Business School, Dublin City University \\ ${ }^{3}$ School of Management, University of Bath
}

\begin{abstract}
We use ultra high frequency (trade by trade) data to demonstrate that equity price clustering and pricing predictability around psychologically important prices in Greece switches away from drachma-focused with the introduction of the euro, but does not immediately switch to euro-clustering. The change in trader price focus around the euro introduction addresses an open debate in the clustering literature on whether the presence of clustering is a bias related to current prices or anchoring to past prices. Our findings of a decline in drachma clustering, but lack of switch to euro effects supports the case for clustering being a trading feature that is slow to transfer to new pricing regimes. A key advantage of the ultra high frequency dataset is we are also able to demonstrate the presence of psychological pricing barriers related to each currency that are not detectable in daily data.
\end{abstract}

Keywords: clustering, psychological barriers, euro introduction, transaction data Jel Classification: G02, G14

\footnotetext{
${ }^{*}$ Corresponding author: Christos Alexakis, Rennes School of Business, 2 rue Robert d'Arbrissel, 35065 Rennes, France. Email: christos.alexakis@esc-rennes.com.
} 


\section{Introduction}

We examine the crossover of stock prices in Greece from being denominated in drachma (up to 30th December 2000) to being denominated in euro (from 2nd January 2001) in order to gain new insights into the presence and cause of price clustering and psychological price barriers in equity markets. Applying an ultra

high frequency trade-by-trade dataset of transactions before and after the change to euro-denomination we are able to use this external market event of a currency conversion to distinguish between a range of frequently proposed explanations for price clustering and psychological barriers.

Price clustering is a phenomenon in financial markets where prices tend to be observed more frequently at some numbers than others. This feature has been observed widely in equity markets, as well as a range of other financial markets. Price clustering has been identified in stock price levels (Donaldson and Kim, 1993; Brown and Mitchell, 2008; Hu et al., 2017), the gold market (Ball et al., 1985), oil markets (Narayan et al., 2011), real estate (Palmon et al., 2004), as well as in more specialist markets such as carbon credits (Palao and Pardo, 2012), water markets (Brooks et al., 2013), and credit default swaps (Meng et al., 2013).

A related, but distinct issue, is that of psychological price barriers. Building on price clustering, psychological barriers research argues that there are key price levels that investors pay attention to, and argues that prices moving through these levels can influence subsequent trading due to increased investor attention. An example of a price barrier would be the Dow Jones Industrial Average (DJIA) moving up through the 20,000 level. The idea is that investors will view the breach of the 20,000 level 
as somehow meaningful and significant as it is a prominent price point and this will influence trading around that barrier level. Donaldson and Kim (1993) formally investigate the impact of psychological barrier breaches in the DJIA and find there is anomalous trading following barrier breaches of rounded 100 prices (e.g. prices such as 2,100, 2,200), with prices predictably rising further following rising through a psychological barrier and falling further after falling through a barrier. Recent studies by Aragon and Dieckmann (2011), Woodhouse et al. (2016), and Berk et al. (2017) confirm the initial finding of Donaldson and Kim (1993) that psychological barriers are a feature of equity pricing. Even more so than price clustering, the presence of psychological barriers has clear implications for market efficiency due to the implied predictability of price movements. Psychological barriers effects have also been found across a range of financial markets outside of equities, including oil (Dowling et al., 2016), gold (Aggarwal and Lucey, 2007), and a range of metal commodities (Cummins et al., 2015).

An issue in studies on price clustering and psychological barriers is understanding why such pricing effects might be evident, and this is the issue to which we address this study using a novel dataset and setting. A number of explanations have been proposed for clustering. An initial explanation was that of microstructure effects; that there is some feature in market structures that leads prices towards being quoted more at certain digits than others (Niederhoffer, 1965). This could include minimum tick sizes defaulting prices to ending in certain digits. This argument has largely faded away as markets have, over time, become evidently more efficient at the transactional level and yet clustering has remained. For example, Ohta (2006) use tick-by-tick Japanese equity data to show strong price clustering around prices 
ending in 0 and 5 yen despite minimum tick size being one yen and only the most liquid stocks being tested.

The two main current explanations for the presence of clustering, and by extension psychological barriers in the sense they they explain investor attention to price levels, are the attraction hypothesis and the aspiration hypothesis. The attraction hypothesis says that investors, faced with bounded rationality, show a preference for rounded numbers and pay greater attention to such numbers. Thus there is greater prevalence of prices ending in 0 or 5 digits, followed by even digits, and lastly odd digits (Niederhoffer, 1965; Ohta, 2006). This feature of pricing has important implications for the price discovery process of an asset, as it implies that market agents tend to trade on more salient or memorable numbers when submitting an order or quoting a price. As a consequence, prices are (at least temporarily) deviated from their true value, with implications for factors such as stock price volatility which in turn affects asset valuation and investment strategies. A related perspective takes the view that the presence of uncertainty in investor decision making reduces incentives to search for a precisely correct stock price. This leads to prices being priced at rounded numbers as a preference compared to the feasible range of other ending digits. As such the theory is a feature of current pricing; in that with reference to the feasible range of current prices, rounded numbers are chosen as a preference.

The alternative proposal, the aspiration level hypothesis, incorporates anchoring to develop a historically driven perspective on clustering. Under this theory investors set a target sell price when buying an equity or at some point in their ownership of the equity, and this tends to be a rounded price point, leading to eventual trading at these rounded price points. Analysts also set target prices in similar rounded price 
points which further influences the setting of rounded price aspiration targets.

The difference then between the aspiration level hypothesis and the attraction hypothesis is that for the aspiration level hypothesis the reason for clustering is historic, while for the attraction hypothesis the reason for clustering is current. While this is normally difficult to distinguish in terms of testing as we just have the actual traded prices, the crossover from national currency to the euro in a number of European countries provides an interesting natural experiment setting in which to test between the two hypotheses. Namely, if the aspiration level hypothesis holds then post the introduction of the euro clustering should remain, at least for a while, influenced by the original currency as aspiration levels will have been set in this currency. There will be a slow decay in influence of the original currency as new trades lead to price aspiration levels being increasingly priced in the new currency. If the attraction hypothesis holds then clustering should quickly switch from being determined by the old currency to being determined by the new currency.

Our paper addresses these issues of alternative interpretations through focusing on the period around the original introduction of the euro currency in 2001 in Greece, using Greek equities as a setting. On 30th December 2000 the Athens Stock Exchange closed with prices denominated in drachmae and on 2nd January 2001 the market opened with all stock prices denominated in euros. With the introduction of the euro currency, a conversion occurred in Greece of all prices at a fixed rate of 1 euro equals 340.75 drachma, implying a stock previously priced at, say, 10,000 drachmae would have opened for euro-denominated trading repriced at $€ 29$. The relevant minimum tick sizes switched from 5 drachma to $€ 0.02$ at this time ${ }^{1}$. In the presence

\footnotetext{
${ }^{1}$ These were the tick sizes for the most common price range of stocks, the tick sizes for low priced stocks changed from 1 drachma to $€ 0.01$
} 
of clustering we would expect that prices were not evenly spread across multiples of 5 drachma in the drachma period (for the 20 possible price endings for the last two digits of prices between 00 and 95), nor evenly spread across the 50 possible last two digits for prices during the $€ 0.02$ tick size euro period. The open issue is the speed with which clustering switches from being drachma to euro denominated.

Sonnemans (2006) previously investigated the change in price clustering around the euro introduction for the Netherlands stock market, and found that day-end price clustering changed from Dutch guilders focused to euro focused immediately upon changing the currency denomination of prices on the Amsterdam stock exchange. We make a number of advances on this study. Sonnemans (2006) only examines the period before crossover and up to the end of the period when guilders were still in use in the domestic economy for normal transactions. We explore all of this period, but also the period when both equity prices and cash in the economy had fully switched to euro. We also use ultra high-frequency trade-by-trade data for the five most traded stocks on the Athens stock exchange over the crossover period (1998-2003) to see if the evidence of a crossover of clustering remains at this micro level for a total of about 9 million transactions. This trade-by-trade data offers new insights into the nature of clustering, beyond just gaining greater understanding of the crossover effect, as the day-end prices frequently used in clustering studies such as Sonnemans (2006) can be anomalous compared to prices during the rest of the day (Comerton-Forde and Putniṇš, 2011). We are further able to better assess speed of adjustment due to the frequency of our data.

The main contribution of our paper, however, is that we also investigate the nature of psychological price barriers both before and after the introduction of the euro, 
something which has not previously been studied. This is an interesting angle as it is not clear a priori whether investors who previously, say, viewed prices crossing whole 1,000 drachma price levels as psychologically significant will automatically switch to, say, viewing $€ 1$ price levels as now significant. Such a study, therefore, informs the prior research on psychological barriers by determining how quickly investors switch their reference points of significant price levels when there is a change in pricing fundamentals. As we have ultra high frequency data for the testing we are not confined to the standard approach of testing daily closing prices, with the limitations that entails, and can instead investigate the impact on subsequent trades following a crossing of a psychologically important price barrier. Our paper is the first paper to investigate the impact of psychological price barriers at the trade-by-trade level and thus contributes to a deeper understanding of this whole area of research, primarily through assessing the trading relevance of psychological barriers and confirming that the feature is not an artifact of closing prices.

The remainder of the paper is structured as follows. The data and methodology is presented and justified in Section 2. The results and analysis are in Section 3, and Section 4 concludes.

\section{Data and methodology}

\subsection{Data}

Our dataset is trade-by-trade prices for the five most traded equities on the Athens Stock Exchange in Greece at the time of the introduction of the euro ${ }^{2}$. The time

\footnotetext{
${ }^{2}$ The equities are: OTE, National Bank of Greece (NBG), Alpha Bank, Hellenic Petroleum (HelPe), Vodafone Hellas (Vodafone)
} 
period runs from 1 January 1998 to 31 December 2003, allowing three years of data on either side of the introduction of the euro on 1 January 2001. During this period the Greek stock market operated under an order-driven continuous auction mechanism. Shares were owned about 30 percent by Greek private investors, 40 percent by Greek institutions, and 30 percent by foreign investors and institutions ${ }^{3}$. There are about 6 million transactions involving the five equities during the drachma period and about 3 million transactions during the euro period. This equates to about 100 trades per five minute trading window in the early period, and 50 trades over the same window in the later period. The lower number of transactions in the second time period appears to be related to the Greek stock market falling over $60 \%$ over this period following a bubble in the first time period that peeked in September 1999. Given the trade-by-trade nature of our testing, this broad market movement should not influence our findings.

\subsection{Price clustering methodology}

Price clustering is assessed in this paper primarily through barrier proximity tests. These tests detect whether price observations around certain price points conform to what would otherwise be expected from a uniform distribution. We can illustrate this with an example of an equity that varies between $€ 8$ and $€ 35$ over a time period. The presence of price clustering could be demonstrated by showing anomalous frequency of prices around two strata of price barrier levels for this equity. The first is prices clustering around whole euro levels (e.g. $€ 8, € 9, € 10 \ldots € 35$ ), and whole $€ 10$ levels, in our case the levels of $€ 10, € 20$, and $€ 30$. Frequency of prices

\footnotetext{
${ }^{3}$ Data from the Athens Stock Exchange Fact Book 2002
} 
might either be anomalously high or anomalously low around barrier levels, but an expectation based on prior research is that there will be a lower frequency around significant barrier levels (Donaldson and Kim, 1993) as these act as resistance and support levels with traders more reluctant to trade close to these levels. The second strata of clustering is at the micro-level around the ending digits of prices. Clustering can be observed at this level by higher frequency around the low-level digits (e.g. ending digits of 5 or 0 in prices) due to the rounding phenomenon (Ikenberry and Weston, 2008). This latter is a particularly interesting feature given that we have trade-by-trade data and thus can examine the impact of rounding at this level, something which the previous investigation of clustering around the euro crossover by Sonnemans (2006) was unable to test due to using daily prices. Thus, we test for both clustering features - high frequency of clustering at low-level ending digits and low clustering around significant price barriers.

For the specification of price barriers, we consider two criteria; first the price range of the stocks and second the availability of currency denominations. During the drachma era we consider the 10s, 100s and 1000s digits, while in the euro era we examine the decimals digits and the 1 s digits. These tests examine two-digit pairs that are constructed from each variable. For example, and referring to the drachma era, the 10s digits examine the two-digit pair to the left of the decimal point (i.e. the decades or - -XX.-). Similarly the 100s digits examine the two-digit pair to the left of the first digit to the immediate left of the decimal point (i.e. the hundreds or -XX-.-) and the 1000s digits examine the thousands (XX-.-). Moving to the euro era, the decimal digits are defined as the two-digit pairs to the immediate right of the decimal point (i.e. the eurocents or -.XX) whereas the 1s digits are defined as 
the two digits that bracket the decimal point (i.e. $-\mathrm{X} . \mathrm{X}-$ ). For each of the previously mentioned barriers we utilize a range of barrier regions; 5, 10, and 15, besides the strict test on the exact barrier that may be denoted as 0. Hence assuming a price of 100 drachmae, the barrier regions are defined as 100 drachmae for the strict test, then a price range of 95-105 for the 5 barrier region, 90-110 for the 10 barrier region, and 85-115 for the 15 barrier region.

The barrier proximity test is carried out using two approaches; a Panel Poisson model and a Panel OLS model. In both cases we are testing variations of the equation:

$$
f(M)=\alpha+\beta D^{i}+\varepsilon
$$

where $f(M)$ is either the absolute or relative frequency of transactions and $D$ is a binary variable taking the value of 1 when the price is within the examined barrier region and 0 otherwise.

The Panel Poisson allows us to explicitly take account of the fact that we are working with count data, while addressing the potential misspecification of a normal error distribution. We use absolute frequency of pricing for $f(M)$ and include robust errors. The secondary approach we follow is a Panel OLS with bootstrapping (1000 repetitions per dummy variable; Cameron and Trivedi (2005)) as adopted from the prior literature (Donaldson and Kim, 1993). In the OLS testing we examine relative frequency of the digits under investigation. In both cases, under the null hypothesis of no barriers, the estimated coefficient on the binary variable will be zero. Rejection of the null against a two-sided alternative would give prima facie evidence for the existence of clustering. Separate tests are run for the drachma and euro period in 
order to identify currency-specific effects, and the tests are also rerun for drachmaconverted levels in the euro period and euro-converted levels in the drachma period.

\subsection{Psychological barriers methodology}

The existence of rounding clustering in prices, although important for price discovery, does not necessarily have particularly strong implications for the trader or investor except to the extent that it speaks about market efficiency. However, clustering around price barriers could be indicative of abnormal trading around these barriers and thus can have direct implications for traders. For example, technical analysts have used the terms support and resistance lines to refer to the differentiated response of stock market returns when psychological barriers are approached. Psychological barriers can be approached by rising or falling prices, so we can test for different price behaviors depending on whether the barrier was breached through a rise or fall. We can also test what happens after a barrier has been breached through rising or falling prices. For these tests we use the trade-by-trade data for the main tests to determine the impact of crossing a price barrier on subsequent trades, and also run tests on daily closing prices to see if there is any impact on future daily returns from crossing a barrier. To examine these conditional effects, we use an OLS framework with four indicator variables that identify certain conditions based on whether the barrier is approached from rising or falling prices and what happens to the share price

following the barrier breach. Specifically, and in line with Dowling et al. (2016), we introduce the following four indicator variables:

- $B D B^{n}$ : Value of 1 in the $n$ trades/days before a downward barrier breach, 0 otherwise 
- $A D B^{n}$ : Value of 1 in the $n$ trades/days after a downward barrier breach, 0 otherwise

- $B U B^{n}$ : Value of 1 in the $n$ trades/days before an upward barrier breach, 0 otherwise

- $A U B^{n}$ : Value of 1 in the $n$ trades/days after an upward barrier breach, 0 otherwise

where $n$ denotes the number of trades or days (depending on whether we are using trade-by-trade or daily data) before or after the particular breach as a measure of responsiveness of market reaction to barrier breaches. We choose values of $n=1$, $2,3,4,5$ trades in order to track the impact on up to the following five trades, and do the same for daily data but just report $n=1,2,5$ days to keep the table sizes manageable ${ }^{4}$. For trade-by-trade data we group all transactions across the five equities together although subsequent trades following a barrier breach for a particular equity are always for the same equity. For the daily data we test the equities individually. Our testing also includes a first-order autoregressive term for potential autocorrelation in the returns. Formally the equation tested is therefore:

$$
R_{t}=\beta_{0}+\beta_{1} R_{t-1}+\beta_{2} B D B_{t}^{n}+\beta_{3} B U B_{t}^{n}+\beta_{4} A D B_{t}^{n}+\beta_{5} A U B_{t}^{n}+\varepsilon_{t}
$$

As we are primarily interested in the differential reaction of market players following the introduction of the euro, we estimate the above regression separately for the drachma and euro periods. For the daily data we also estimate the regression using drachma-denominated levels in the euro period and euro-denominated levels in the drachma period.

\footnotetext{
${ }^{4}$ The purpose of these selected days is to report the immediate impact and the impact over the space of a week. The omitted results were qualitatively similar to the reported results and are available upon request.
} 


\section{Empirical findings}

\subsection{Price clustering}

The core findings for clustering are contained in Tables 1 and 2 and Figure 1, with the tables comprising the Panel Poisson regressions for drachma and euro respectively, and each divided into the sub-periods of 1998-2000 and 2001-2003. Tables 3 and 4, report the drachma and euro findings applying OLS regressions in line with the prior

literature. These findings confirm that clustering is a major feature in the pricing of Greek equities over the time period studied, but particularly before the crossover to euro pricing. This can be seen graphically in Figure 1 for 100s drachma and decimal digits of euro. Panel A shows clustering in drachma during the drachma period with spikes in clustering around 00 and 50 prices, followed by individual 10s of drachma. Clustering around drachma-equivalent euro levels is not a feature of the euro period as seen in Panel B. Clustering is also somewhat evident around decimal digits of euro during the euro area, with larger frequencies in the 0 range and 40-60 range, but the effect is not as pronounced as for drachma clustering.

Turning to the formal results, for the OLS drachma results in Table 1 traded prices clustered strictly around whole values of 10 drachma (Pseudo R-square $=$ 0.82 ) and 100 drachma (Pseudo R-square $=0.70$ ) in the 1998-2000 period despite the minimum tick size being just 5 drachma. There was also negative clustering around 1000 drachma prices, showing a lower than expected frequency of prices around these larger price levels. This finding of positive price clustering in low digits and negative price clustering in significant barrier regions such as 1000 drachma, is in line with previous findings on clustering, albeit that our study also shows this 
to be present using ultra high frequency data. The results for euro over the same 1998-2000 period in Table 2 confirm, as expected, essentially no euro-denominated clustering during the period when prices were in drachma. We might have seen some euro clustering during this period if traders and investors had switched over their trading systems to euro pricing before the official switch, but this was evidentially not the case ${ }^{5}$. The OLS findings in Tables 3 (drachma) and 4 largely echo these findings.

The findings for the period 2001-2003 after the switchover to euro pricing show a mixture of declining but continued drachma clustering, and mixed evidence of new euro clustering. In Table 1 for the Poisson tests we see some evidence that prices continue to cluster around 10s of drachmae (Pseudo R-square $=0.25$ ). Although in general, drachma clustering is significantly decreased. This can also be seen in the OLS results in Table 3, where there is a continued presence of drachma clustering but evident decline in importance as seen in the R-square values. Table 2 (Poisson) and 4 (OLS) give mixed findings for euro price clustering. The OLS results suggest new clustering around the decimal digits of euros (R-square $=0.50$ for the strict price point), although the clustering around 1s of euros remains minor. The Poisson results, however, show no support for any new euro clustering. Given that Poisson model is better specified as it is an explicit count model, and despite the prevalence of OLS testing of barrier proximity in past papers, we are minded more towards the Poisson finding of no new euro clustering. There are thus two interesting findings here. First, that clustering continued to be denominated in drachma despite the

\footnotetext{
${ }^{5}$ Due to the nature of testing individual trades at volume, the significance levels are not a good measure of economic significance due to very low standard errors associated with a very large number of observations $(n)$. The $\mathrm{R}$-square values are a better way to assess the importance of clustering as they are not influenced by the number of observations.
} 
switchover to euro, and second that euro clustering did not immediately start being a feature of pricing. This suggests that, to some extent, prices continued to be viewed in terms of drachma even after the switchover to euros implying at least an informal dual euro/drachma pricing by traders. We thus have evidence of a sluggishness in switching over to the new euro pricing framework and support for the aspiration level hypothesis.

We now look in more detail at the evolution of clustering over time in order to understand the nature of the crossover from drachma to euro clustering. We repeat the clustering analysis using a rolling estimation. Specifically, Equation 1 is re-estimated on a daily rolling regression basis throughout the entire sample, while testing for the existence of drachma and euro price clustering. Figure 2, Panel A, plots the adjusted R-square for the full set of rolling regressions for each of the five stocks for drachmae clustering (100s digits) and Panel B repeats for the case of euro clustering (decimal digits). The time evolution of the barriers shows graphically how quickly clustering switched from being drachma denominated during the drachma period, to not being a major feature of pricing post the switch in stock currency denomination. A similar but weaker effect is seen in Panel B for euro clustering around the switchover to euro pricing.

In order to formally detect for breaks in clustering, we regress the average adjusted R-square of the five stocks on a constant and a linear trend while allowing for an endogenous breakpoint detection following Bai and Perron (2003). The results of this regression are presented in Table 5. The endogenous breakpoint detection identifies three periods; two are during the drachma period, while the third extends from the last month of the drachma circulation onwards. We can also see this break from 
a visual inspection of Figure 2 Panel A, which suggests that in the second period $(18 / 8 / 1999-5 / 12 / 2000)$ the strength of price clustering is reducing compared to the first, possibly reflecting the simultaneous use of the two currencies during this year. Drachmae price clustering at the 100s level drops out of significance about a month prior to the establishment of the euro as the sole currency in Greece. The euro barriers gain significance once the euro is introduced. However, this seems to be a gradually phased in process across the years of the implementation. Moreover, some idiosyncratic stock characteristics can affect the speed in which the new price barrier levels become significant. For example, price barriers for Alpha Bank are created faster than Vodafone as shown by the immediate rise in the significance of the euro price barriers following the euro adoption in the case of the former versus a belated rise in the latter case.

\subsection{Psychological barriers}

Table 6 shows the estimated coefficients and standard errors for the regression testing

for conditional effects (Equation 2) using trade-by-trade data and estimated over the drachma (Panel A, 100s drachma) and euro periods (Panel B, 1s euro).

The coefficients for ADB and AUB are of primary interest as they denote the market reaction following a barrier breach. Hence, any statistical significance on these indicator variables would give prima facie evidence that following a barrier breach there is an abnormal return. First, in the drachma period for 100 drachma levels, the ADB coefficient suggests that after a downward barrier breach returns drop in the following trade, then bounce up for trades 2-5 with decreasing strength. Conversely, the AUB coefficient suggests that after an upward barrier breach the 
return climbs further during the following trade, then decreases for trades 2-5 with decreasing strength. In the euro period and crossing of whole euro barrier points, the findings are similar with two key differences. First, in the magnitude of the statistical significance of the AUB and ADB variables, this is noticeably lower compared to the drachma period. For instance, the ADB coefficient for the following trade $(n=1)$ are equal to -0.0232 and -0.0089 in the drachma and euro periods respectively. Second, the persistence of the effect following a barrier breach appears to be shorter lived by approximately 1 trade compared to the drachma period. Thus, the ADB coefficients retain their statistical significance up to 5 trades following a breach whereas under the euro period significance is retained for 4 trades.

Panel C of Table 6 presents a series of statistical significance tests for each reaction window between the coefficients pertaining to the drachma and those of the euro periods. It can be inferred that there is indeed a differential market response due to the change in the currency and the associated relocation of the psychological barriers. The core finding is that the drachma effects are larger than the euro effects. Of the four reactions denoted by the respective indicator variables, those following a barrier breach are those that show the most significant. These findings, combined with the findings for clustering, suggest that after a changeover to a new pricing regime it takes traders a period of time to start being influenced by new psychological barriers.

A last analysis we run is tests for the presence of daily psychological barriers, this analysis is run for each equity individually and is reported in Tables 7-11. These tests cover 100s and 1000s barrier levels of drachma and 1s and 10s of euro. Euro-converted barrier levels are also tested in the drachma period, and similarly drachma-converted barriers are tested in the euro period. 
The main finding is of minor significance across all the barrier levels and all the currencies. For the few significant findings that are present the weak pattern is of significant euro barriers in the euro period. For example, in Table 8 we find that prices fall back in the subsequent week after rising through a whole $€ 10$ barrier for the National Bank of Greece stock.

As we are testing 1,000 coefficients across all five tables ${ }^{6}$ there is a considerable probability that even the reported significance findings for the daily psychological barriers are there by chance. To account for the potential that the significant findings we have are there by chance we run a Generalised Bonferroni p-value correction as proposed by Romano et al. (2010) which adjusts the acceptable p-value level to account for the number of coefficients tested using the formula $\hat{p}_{(i)} \leq \alpha_{(i)} \equiv k \cdot \alpha / s$ where $\mathrm{s}$ is the total number of coefficients tested (1,000 in our case), $k$ is the number of false discoveries we wish to control for, and $\alpha$ is the significance level. We follow Berk et al. (2017) and set $k$ at 5 percent or 50 coefficients, and $\alpha$ at 10 percent, meaning the Bonferroni corrected p-value is 0.005 .

When we re-examine Tables 7-11 with this new p-value as the null rejection level, we find that only four of the barrier variables, including the three $€ 10$ time variables for National Bank of Greece noted above, remain significant. This suggests that daily psychological barriers are not a major feature in pricing, and shows the advantage of our transaction level psychological barriers tests, which were able to capture the impact of crossing barriers on subsequent trading at the micro-level.

\footnotetext{
${ }^{6}$ Five variables per time period $\mathrm{x}$ two time periods $\mathrm{x}$ five equities $\mathrm{x}$ five days (although only three days are reported) x 4 currency barriers $(2$ drachma, 2 euro $)=1,000$ coefficient tests.
} 


\section{Conclusions}

With our dataset of ultra high frequency trades for the five largest equities in Greece at the time of the crossover from the drachma to the euro currency we demonstrate a currency-related crossover of the presence of psychological barriers, but continued presence of clustering in the old currency.

This finding builds on the findings of Sonnemans (2006) for the Dutch market, but also takes the research a number of significant steps forward. First, we extend testing into a period when there is only euro pricing, as opposed to a period of dual euro-original currency pricing as studied by Sonnemans (2006). Second, we use transactions data as opposed to problematic daily closing prices to provide rolling regression estimates of how clustering reacts to the changeover to the euro. We show a significant reduction in drachma clustering upon adopting the euro, but that it continued to be a presence for at least the three years after crossover to euro pricing. Third, we are also able to use our dataset to identify that euro-focused clustering

did not become a feature immediately after adoption of the euro, suggesting that clustering is a learned behaviour and it takes investors time to adopt new clustering practices. Our speed of currency crossover findings support the conclusion that clustering seems to be mainly related to anchoring to past prices supporting the aspiration level hypothesis.

The other novel set of contributions of the work is in the investigation of pricing behavior following the crossing of a psychologically important price point. Here we once again use the transaction level data and are able to show an influence on subsequent trades following a trade that crosses a barrier level. The normal 
behavior we observe being that the subsequent trade continues the price trend and the following trades lead to a partial reversal. That we are able to show the presence of predictable trading following breach of a barrier at the transaction level, as opposed to daily prices as applied in the prior research, is an interesting contribution in itself with wider application, but we also demonstrate a crossover of the relevant barriers upon change of currency. Our daily data psychological barrier results suggest that daily data tests miss the presence of these barriers and the impact of currency crossover, as psychological barriers are not found to be present at the daily level.

Recent research is increasingly identifying the presence and importance of clustering and psychological barriers across a whole range of financial markets outside of equities. Our research therefore informs the development of this stream, by showing that clustering retains links to past pricing and transfers to current pricing in a slow manner, and arguing that the standard practice of seeking to identify psychological barriers using daily data can miss important transaction level predictability in pricing caused by these barriers. This last aspect is particularly important as the bulk of equity speculation rapidly moves to the ultra high frequency level away from the longer trading horizons of the past.

We end the study by noting a limitation of this research. Despite our tests being at the trade-by-trade level we are still not able to distinguish which type of traders are more likely to engage in price clustering or trade in particular ways around psychologically important price points as we don't have any trader identifications attached to trades. It was noted in the data section that investment in Greek equities consists of about 30\% Greek retail investors, 40\% Greek institutional investors, and $30 \%$ foreign investors. It would have been informative to know if a certain group of 
these investors was driving our findings. This would speak to whether the patterns were caused by, for example, professional trading habits, by sizes of transactions, or by behavioral factors such as risk aversion or risk seeking relative to reference points. We suggest this disaggregation of trades by trader type approach to future research, subject to data availability, and it is an area we intend to also explore in a future study. 


\section{References}

Aggarwal, R. and B. M. Lucey (2007). Psychological barriers in gold prices? Review of Financial Economics 16(2), 217-230.

Aragon, G. O. and S. Dieckmann (2011). Stock market trading activity and returns around milestones. Journal of Empirical Finance 18(4), 570-584.

Bai, J. and P. Perron (2003). Computation and analysis of multiple structural change models. Journal of Applied Econometrics 18(1), 1-22.

Ball, C. A., W. N. Torous, and A. E. Tschoegl (1985). The degree of price resolution: The case of the gold market. Journal of Futures Markets 5(1), 29-43.

Berk, A. S., M. Cummins, M. Dowling, and B. M. Lucey (2017). Psychological price barriers in frontier equities. Journal of International Financial Markets, Institutions and Money 49, 1-14.

Brooks, R., E. Harris, and Y. Joymungul (2013). Price clustering in Australian water markets. Applied Economics 45(6), 677-685.

Brown, P. and J. Mitchell (2008). Culture and stock price clustering: Evidence from The Peoples' Republic of China. Pacific-Basin Finance Journal 16(1), 95-120.

Cameron, A. C. and P. K. Trivedi (2005). Microeconometrics: Methods and applications. Cambridge University Press: Cambridge.

Comerton-Forde, C. and T. J. Putninšs (2011). Measuring closing price manipulation. Journal of Financial Intermediation 20(2), 135-158.

Cummins, M., M. Dowling, and B. M. Lucey (2015). Behavioral influences in nonferrous metals prices. Resources Policy 45, 9-22. 
Donaldson, R. G. and H. Y. Kim (1993). Price barriers in the Dow Jones Industrial Average. Journal of Financial and Quantitative Analysis 28(03), 313-330.

Dowling, M., M. Cummins, and B. M. Lucey (2016). Psychological barriers in oil futures markets. Energy Economics 53, 293-304.

Hu, B., C. Jiang, T. McInish, and H. Zhou (2017). Price clustering on the Shanghai Stock Exchange. Applied Economics 49(28), 2766-2778.

Ikenberry, D. L. and J. P. Weston (2008). Clustering in US stock prices after decimalisation. European Financial Management 14(1), 30-54.

Meng, L., T. Verousis, and O. ap Gwilym (2013). A substitution effect between price clustering and size clustering in credit default swaps. Journal of International Financial Markets, Institutions and Money 24, 139-152.

Narayan, P. K., S. Narayan, and S. Popp (2011). Investigating price clustering in the oil futures market. Applied Energy 88(1), 397-402.

Niederhoffer, V. (1965). Clustering of stock prices. Operations Research 13(2), 258265.

Ohta, W. (2006). An analysis of intraday patterns in price clustering on the Tokyo Stock Exchange. Journal of Banking \& Finance 30(3), 1023-1039.

Palao, F. and A. Pardo (2012). Assessing price clustering in European carbon markets. Applied Energy 92, 51-56.

Palmon, O., B. Smith, and B. Sopranzetti (2004). Clustering in real estate prices: Determinants and consequences. Journal of Real Estate Research 26(2), 115-136. Romano, J. P., A. M. Shaikh, and M. Wolf (2010). Hypothesis testing in econometrics. Annual Review of Economics 2(1), 75-104.

Sonnemans, J. (2006). Price clustering and natural resistance points in the Dutch 
stock market: A natural experiment. European Economic Review 50(8), 19371950.

Woodhouse, S. A., H. Singh, S. Bhattacharya, and K. Kumar (2016). Invisible walls: Do psychological barriers really exist in stock index levels? The North American Journal of Economics and Finance 36, 267-278. 

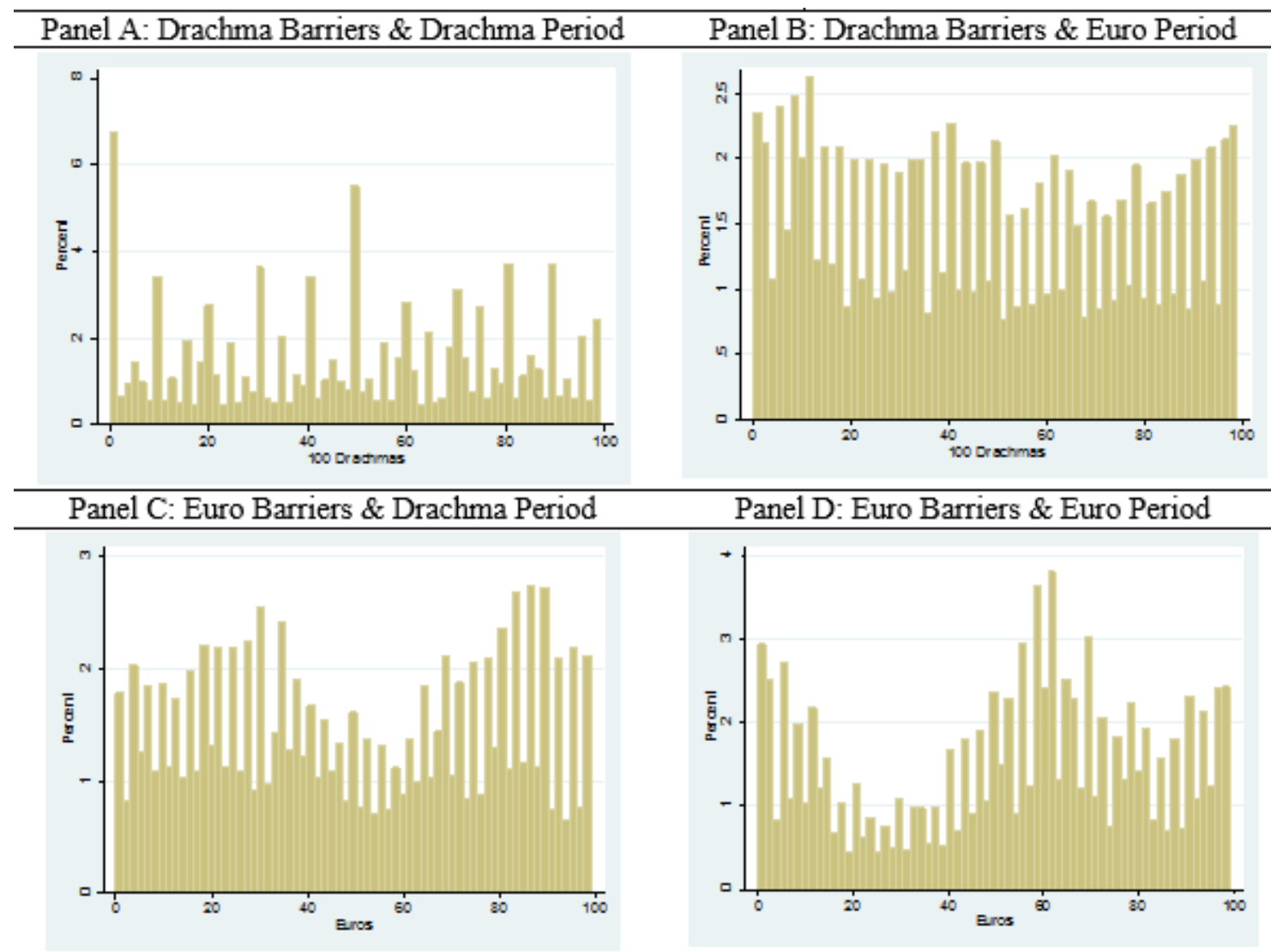

Figure 1: Frequency distribution of drachma 100s and euro decimal digits. (All Stocks) 

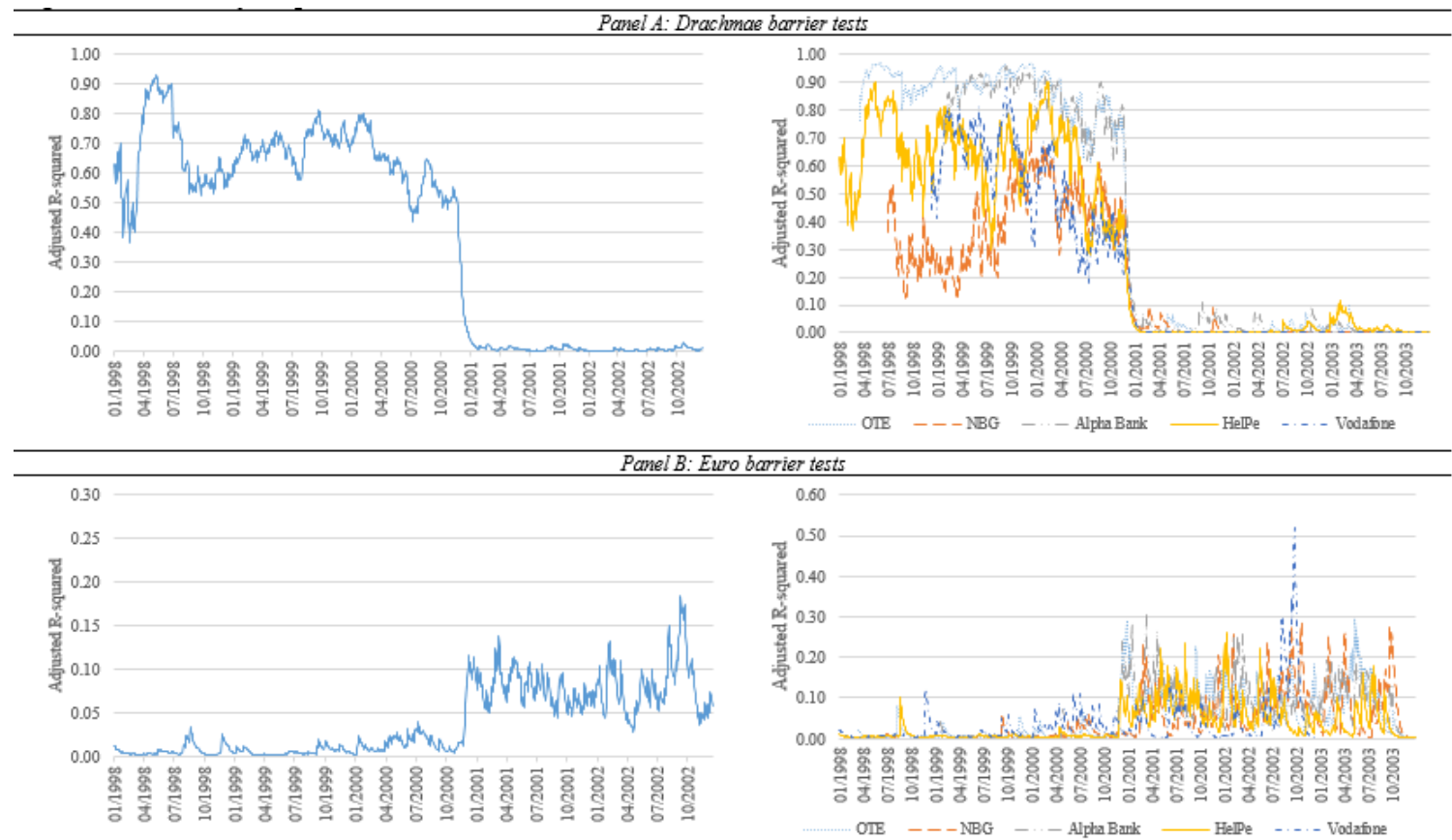

Figure 2: Evolution of clustering over time. The figure plots the average R-squared of the five stocks from the barrier proximity tests (see Tables 1 and 2) [left] and for the individual stocks [right]. Panel A presents the case of the Drachma denominated period and Panel B repeats for the Euro period. 
Table 1: Panel Poisson: Absolute clustering in Greek equity prices (drachma)

\begin{tabular}{|c|c|c|c|c|c|c|c|c|}
\hline & \multicolumn{4}{|c|}{ Years: 1998-2000 } & \multicolumn{4}{|c|}{ Years: 2001-2003 } \\
\hline & $n=0$ & $n=5$ & $n=10$ & $n=15$ & $n=0$ & $n=5$ & $n=10$ & $n=15$ \\
\hline & \multicolumn{8}{|c|}{ A. 10 s digits } \\
\hline beta & $1.573^{* * *}$ & $1.197^{* * *}$ & $0.996^{* * *}$ & $0.886^{* * *}$ & $2.144^{* * *}$ & $0.569 * * *$ & $0.422^{* * *}$ & $0.326^{* * *}$ \\
\hline SE & 0.046 & 0.016 & 0.010 & 0.026 & 0.177 & 0.074 & 0.031 & 0.018 \\
\hline \multirow[t]{2}{*}{ Pseudo R-Square } & 0.82 & 0.44 & 0.26 & 0.16 & 0.25 & 0.05 & 0.03 & 0.02 \\
\hline & \multicolumn{8}{|c|}{ B. 100 s digits } \\
\hline beta & $0.978^{* * *}$ & $0.851^{* * *}$ & $0.695^{* * *}$ & $0.630^{* * *}$ & $1.086^{* * *}$ & $0.463^{* * *}$ & $0.467^{* * *}$ & $0.383^{* * *}$ \\
\hline $\mathrm{SE}$ & 0.008 & 0.017 & 0.023 & 0.029 & 0.050 & 0.031 & 0.028 & 0.018 \\
\hline \multirow[t]{2}{*}{ Pseudo R-square } & 0.70 & 0.51 & 0.30 & 0.20 & 0.20 & 0.20 & 0.23 & 0.13 \\
\hline & \multicolumn{8}{|c|}{ C. 1000 s digits } \\
\hline beta & $-0.029 * * *$ & $-0.064^{* * *}$ & $-0.083^{* * *}$ & $-0.128^{* * *}$ & $0.028^{* * *}$ & $-0.006^{* * *}$ & $-0.007 * * *$ & $-0.041 * * *$ \\
\hline $\mathrm{SE}$ & 0.011 & 0.012 & 0.018 & 0.034 & 0.052 & 0.069 & 0.072 & 0.046 \\
\hline Pseudo R-square & 0.00 & 0.02 & 0.02 & 0.04 & 0.00 & 0.00 & 0.00 & 0.00 \\
\hline
\end{tabular}

Results from the barrier proximity tests using drachma pricing for all Greek equities listed in Section 2 using a Panel Poisson regression with robust errors for absolute frequency of pricing. Results cover period 1998-2003 and are reported in sub-periods of 1998-2000 (pre-crossover) and 2001-2003 (after-crossover). Tests are a regression of $f(M)=\alpha+\beta D^{i}+\varepsilon$. $\mathrm{n}$ is the percentage range of the barrier region, e.g. $\mathrm{n}=10$ is $\pm 10 \%$ of the strict currency barrier level. The barrier ranges are defined as follows: $\operatorname{BR}(0)=00 ; \operatorname{BR}(5)=95,96, \ldots 00, \ldots 04,05$; $\mathrm{BR}(10)=90,96, \ldots 00, \ldots 04,10 ; \mathrm{BR}(15)=85,96, \ldots 00, \ldots 04,15$. The defined barriers are represented by a dummy variable taking the value 1 when the required digits fall in the barrier range and zero otherwise. Each panel focuses on different digits, with Panel A analyzing the 10s digits, Panel B the 100s digits, and Panel $\mathrm{C}$ the 1000s digits. The construction of the digits is explained in section $2.2 .{ }^{*} p<0.10,{ }^{* *} p<0.05,{ }^{* * *} p<0.01$. 
Table 2: Panel Poisson: Absolute clustering in Greek equity prices (euro)

\begin{tabular}{|c|c|c|c|c|c|c|c|c|}
\hline & \multicolumn{4}{|c|}{ Years: 1998-2000 } & \multicolumn{4}{|c|}{ Years: 2001-2003 } \\
\hline & $n=0$ & $n=5$ & $n=10$ & $n=15$ & $n=0$ & $n=5$ & $n=10$ & $n=15$ \\
\hline \multicolumn{9}{|c|}{ A. decimal digits } \\
\hline beta & 0.006 & -0.006 & -0.007 & -0.006 & 0.012 & 0.008 & 0.000 & $0.018^{*}$ \\
\hline SE & 0.004 & 0.006 & 0.010 & 0.010 & 0.030 & 0.020 & 0.009 & 0.009 \\
\hline $\mathrm{R}$-square & 0.00 & 0.00 & 0.00 & 0.00 & 0.00 & 0.00 & 0.00 & 0.00 \\
\hline \multicolumn{9}{|c|}{ B. 1 s digits } \\
\hline beta & $0.031^{* * *}$ & $0.030^{* * *}$ & $0.031^{* * *}$ & $0.021^{*}$ & -0.027 & 0.034 & 0.035 & $0.027^{*}$ \\
\hline SE & 0.004 & 0.008 & 0.009 & 0.010 & 0.022 & 0.023 & 0.022 & 0.012 \\
\hline R-square & 0.00 & 0.00 & 0.00 & 0.00 & 0.00 & 0.00 & 0.00 & 0.00 \\
\hline
\end{tabular}

Results from the barrier proximity tests using euro pricing for all Greek equities listed in Section 2 using a Panel Poisson regression with robust errors for absolute frequency of pricing. Results cover period 1998-2003 and are reported in subperiods of 1998-2000 (pre-crossover) and 2001-2003 (after-crossover). Tests are a regression of $f(M)=$ $\alpha+\beta D^{i}+\varepsilon . \mathrm{n}$ is the percentage range of the barrier region, e.g. $\mathrm{n}=10$ is $\pm 10 \%$ of the strict currency barrier level. The barrier ranges are defined as follows: $\mathrm{BR}(0)=00 ; \mathrm{BR}(5)=95,96, \ldots 00, \ldots 04,05 ; \mathrm{BR}(10)=90,96, \ldots 00, \ldots 04,10$; $\mathrm{BR}(15)=85,96, \ldots 00, \ldots 04,15$. The defined barriers are represented by a dummy variable taking the value 1 when the required digits fall in the barrier range and zero otherwise. Each panel focuses on different digits, with Panel A analyzing the decimal digits and Panel B the 1s digits. The construction of the digits is explained in section 2.2 . $^{*}$ $p<0.10,{ }^{* *} p<0.05,{ }^{* * *} p<0.01$. 
Table 3: Panel OLS: Relative clustering in Greek equity prices (drachma)

\begin{tabular}{|c|c|c|c|c|c|c|c|c|}
\hline & \multicolumn{4}{|c|}{ Years: 1998-2000 } & \multicolumn{4}{|c|}{ Years: 2001-2003 } \\
\hline & $n=0$ & $n=5$ & $n=10$ & $n=15$ & $n=0$ & $n=5$ & $n=10$ & $n=15$ \\
\hline \multicolumn{9}{|c|}{ A. 10 s digits } \\
\hline beta & $0.146^{* * *}$ & $0.112^{* * *}$ & $0.085^{* * *}$ & $0.075^{* * *}$ & $0.176^{* * *}$ & $0.014^{* * *}$ & $0.009 * * *$ & $0.006^{* * *}$ \\
\hline SE & 0.002 & 0.003 & 0.004 & 0.005 & 0.000 & 0.002 & 0.001 & 0.000 \\
\hline R-square & 0.92 & 0.63 & 0.40 & 0.32 & 0.67 & 0.06 & 0.04 & 0.02 \\
\hline \multicolumn{9}{|c|}{ B. 100s digits } \\
\hline beta & $0.026^{* * *}$ & $0.008^{* * *}$ & $0.006^{* * *}$ & $0.004^{* * *}$ & $0.030^{* * *}$ & $0.002^{* * *}$ & $0.002^{* * *}$ & $0.001 * * *$ \\
\hline SE & 0.001 & 0.001 & 0.001 & 0.000 & 0.000 & 0.001 & 0.000 & 0.000 \\
\hline $\mathrm{R}$-square & 0.45 & 0.11 & 0.09 & 0.04 & 0.28 & 0.02 & 0.04 & 0.01 \\
\hline \multicolumn{9}{|c|}{ C. 1000 s digits } \\
\hline beta & $-0.004^{* * *}$ & $-0.005^{* * *}$ & $-0.006^{* * *}$ & $-0.006^{* * *}$ & $-0.003^{* * *}$ & $-0.005^{* * *}$ & $-0.006^{* * *}$ & $-0.007^{* * *}$ \\
\hline $\mathrm{SE}$ & 0.000 & 0.001 & 0.001 & 0.001 & 0.000 & 0.000 & 0.000 & 0.000 \\
\hline $\mathrm{R}$-square & 0.01 & 0.15 & 0.32 & 0.48 & 0.01 & 0.14 & 0.29 & 0.38 \\
\hline
\end{tabular}

Results from the barrier proximity tests using drachma pricing for all Greek equities listed in Section 2 using a Panel OLS regression with bootstrapping for relative frequency of pricing. Results cover period 1998-2003 and are reported in sub-periods of 1998-2000 (pre-crossover) and 2001-2003 (after-crossover). Tests are a regression of $f(M)=$ $\alpha+\beta D^{i}+\varepsilon . \mathrm{n}$ is the percentage range of the barrier region, e.g. $\mathrm{n}=10$ is $\pm 10 \%$ of the strict currency barrier level. The barrier ranges are defined as follows: $\operatorname{BR}(0)=00 ; \operatorname{BR}(5)=95,96, \ldots 00, \ldots 04,05 ; \operatorname{BR}(10)=90,96, \ldots 00, \ldots 04,10$; $\mathrm{BR}(15)=85,96, \ldots 00, \ldots 04,15$. The defined barriers are represented by a dummy variable taking the value 1 when the required digits fall in the barrier range and zero otherwise. Each panel focuses on different digits, with Panel A analyzing the 10s digits, Panel B the 100s digits, and Panel C the 1000s digits. The construction of the digits is explained in section $2.2 .{ }^{*} p<0.10,{ }^{* *} p<0.05,{ }^{* * *} p<0.01$. 
Table 4: Panel OLS: Relative clustering in Greek equity prices (euro)

\begin{tabular}{|c|c|c|c|c|c|c|c|c|}
\hline & \multicolumn{4}{|c|}{ Years: $1998-2000$} & \multicolumn{4}{|c|}{ Years: 2001-2003 } \\
\hline & $n=0$ & $n=5$ & $n=10$ & $n=15$ & $n=0$ & $n=5$ & $n=10$ & $n=15$ \\
\hline & \multicolumn{8}{|c|}{ A. decimal digits } \\
\hline beta & $0.012^{* * *}$ & $0.001^{* * *}$ & $0.001 * * *$ & $0.001^{* * *}$ & $0.011^{* * *}$ & $0.003^{* * *}$ & $0.002^{* * *}$ & $0.002^{* * *}$ \\
\hline SE & 0.000 & 0.000 & 0.000 & 0.000 & 0.000 & 0.000 & 0.000 & 0.000 \\
\hline \multirow[t]{2}{*}{ R-square } & 0.17 & 0.02 & 0.03 & 0.02 & 0.50 & 0.14 & 0.12 & 0.06 \\
\hline & \multicolumn{8}{|c|}{ B. 1 s digits } \\
\hline beta & 0.000 & $0.001^{* * *}$ & $0.001^{* * *}$ & $0.001^{* * *}$ & 0.000 & $0.001^{* * *}$ & $0.000^{* * *}$ & $0.000 * *$ \\
\hline $\mathrm{SE}$ & 0.000 & 0.000 & 0.000 & 0.000 & 0.000 & 0.000 & 0.000 & 0.000 \\
\hline $\mathrm{R}$-square & 0.00 & 0.04 & 0.04 & 0.05 & 0.00 & 0.02 & 0.01 & 0.01 \\
\hline
\end{tabular}

Results from the barrier proximity tests using euro pricing for all Greek equities listed in Section 2 using a Panel OLS regression with bootstrapping for relative frequency of pricing. Results cover period 1998-2003 and are reported in subperiods of 1998-2000 (pre-crossover) and 2001-2003 (after-crossover). Tests are a regression of $f(M)=$ $\alpha+\beta D^{i}+\varepsilon . \mathrm{n}$ is the percentage range of the barrier region, e.g. $\mathrm{n}=10$ is $\pm 10 \%$ of the strict currency barrier level. The barrier ranges are defined as follows: $\mathrm{BR}(0)=00 ; \mathrm{BR}(5)=95,96, \ldots 00, \ldots 04,05 ; \mathrm{BR}(10)=90,96, \ldots 00, \ldots 04,10$; $\mathrm{BR}(15)=85,96, \ldots 00, \ldots 04,15$. The defined barriers are represented by a dummy variable taking the value 1 when the required digits fall in the barrier range and zero otherwise. Each panel focuses on different digits, with Panel A analyzing the decimal digits and Panel B the 1s digits. The construction of the digits is explained in section 2.2 . $^{*}$ $p<0.10,{ }^{* *} p<0.05,{ }^{* * *} p<0.01$. 
Table 5: Structural breaks in clustering over time

\begin{tabular}{lcc}
\hline & Average $R^{2}$ drachma barriers & Average $R^{2}$ euro barriers \\
\hline Constant & Period I: $2 / 1 / 1998-17 / 8 / 1999$ & Period I: $2 / 1 / 1998-28 / 11 / 2000$ \\
Trend & $0.6726^{* * *}$ & $0.0037^{* * *}$ \\
& 0.0429 & 0.0011 \\
& 0.0001 & $0.0002^{* * *}$ \\
& 0.0003 & 0.0001 \\
\hline Constant & Period II: $18 / 8 / 1999-5 / 12 / 2000$ & Period II: $29 / 11 / 2000-30 / 07 / 2002$ \\
& $1.2010^{* * *}$ & $0.1276^{* * *}$ \\
Trend & 0.0429 & 0.0166 \\
& $-0.0009^{* * *}$ & $-0.0001^{* * *}$ \\
\hline Constant & 0.0001 & 0.0001 \\
\hline Trend & Period III: $6 / 12 / 2000-31 / 12 / 2003$ & Period III: $31 / 07 / 2002-31 / 12 / 2003$ \\
\hline$N$ & $0.0434^{* * *}$ & $0.3882^{* * *}$ \\
Adjusted $R^{2}$ & 0.0142 & 0.0523 \\
\hline
\end{tabular}

Table reports estimated coefficients and standard errors in parenthesis of the endogenous breakpoint regression for the average adjusted $R^{2}$ related to the evolution of the price clustering. The table presents the results (estimated coefficients and standard errors) of the Bai and Perron (2003) structural breakpoint test on the average R-squared of the five stocks from the barrier proximity tests (see Tables 2 and 3 ). ${ }^{*} p<0.10,{ }^{* *} p<0.05,{ }^{* * *} p<0.01$. 
Table 6: Psychological barriers and trade-by-trade data

\begin{tabular}{|c|c|c|c|c|c|}
\hline$n$ trades & $n=1$ & $n=2$ & $n=3$ & $n=4$ & $n=5$ \\
\hline \multicolumn{6}{|c|}{ Panel A: Conditional effects during the drachma period (100s drachma) } \\
\hline \multirow[t]{2}{*}{$R_{t-1}$} & $-0.2731^{* * *}$ & $-0.2950^{* * *}$ & $-0.2840 * * *$ & $-0.2831 * * *$ & $-0.2829 * * *$ \\
\hline & 0.005 & 0.005 & 0.005 & 0.005 & 0.005 \\
\hline \multirow[t]{2}{*}{$B D B_{t}^{n}$} & $0.0866^{* * *}$ & $0.0558^{* * *}$ & 0.0010 & -0.0014 & -0.0017 \\
\hline & 0.002 & 0.002 & 0.002 & 0.002 & 0.002 \\
\hline \multirow{2}{*}{$B U B_{t}^{n}$} & $-0.1403^{* * *}$ & $-0.0790^{* * *}$ & $-0.0098^{* * *}$ & $-0.0041^{* *}$ & -0.0017 \\
\hline & 0.002 & 0.002 & 0.002 & 0.002 & 0.002 \\
\hline \multirow[t]{2}{*}{$A D B_{t}^{n}$} & $-0.0232^{* * *}$ & $0.0625^{* * *}$ & $0.0353^{* * *}$ & $0.0154^{* * *}$ & $0.0083^{* * *}$ \\
\hline & 0.002 & 0.002 & 0.002 & 0.002 & 0.002 \\
\hline \multirow[t]{2}{*}{$A U B_{t}^{n}$} & $0.0612^{* * *}$ & $-0.0311^{* * *}$ & $-0.0206^{* * *}$ & $-0.0095^{* * *}$ & $-0.0048^{* * *}$ \\
\hline & 0.002 & 0.002 & 0.002 & 0.002 & 0.002 \\
\hline \multicolumn{6}{|c|}{ Panel B: Conditional effects during the euro period (1s euro) } \\
\hline \multirow[t]{2}{*}{$R_{t-1}$} & $-0.2972^{* * *}$ & $-0.3172^{* * *}$ & $-0.3064^{* * *}$ & $-0.3058^{* * *}$ & $-0.3058^{* * *}$ \\
\hline & 0.009 & 0.009 & 0.009 & 0.009 & 0.009 \\
\hline \multirow[t]{2}{*}{$B D B_{t}^{n}$} & $0.0553^{* * *}$ & $0.0428^{* * *}$ & 0.0020 & -0.0022 & -0.0020 \\
\hline & 0.003 & 0.002 & 0.002 & 0.002 & 0.002 \\
\hline \multirow[t]{2}{*}{$B U B_{t}^{n}$} & $-0.0914^{* * *}$ & $-0.0574^{* * *}$ & $-0.0062^{* * *}$ & 0.0004 & -0.0014 \\
\hline & 0.003 & 0.002 & 0.002 & 0.002 & 0.002 \\
\hline \multirow[t]{2}{*}{$A D B_{t}^{n}$} & $-0.0089 * * *$ & $0.0443^{* * *}$ & $0.0188^{* * *}$ & $0.0069^{* * *}$ & $0.0028^{*}$ \\
\hline & 0.002 & 0.002 & 0.002 & 0.002 & 0.002 \\
\hline \multirow[t]{2}{*}{$A U B_{t}^{n}$} & $0.0439^{* * *}$ & $-0.0255^{* * *}$ & $-0.0109^{* * *}$ & $-0.0048^{* * *}$ & -0.0021 \\
\hline & 0.002 & 0.002 & 0.001 & 0.002 & 0.001 \\
\hline \multicolumn{6}{|c|}{ Panel C: Statistical significance tests (drachma vs euro) } \\
\hline \multirow[t]{2}{*}{$B D B_{t}^{n}$} & $899.230^{* * *}$ & $353.410^{* * *}$ & 0.050 & 0.020 & 0.310 \\
\hline & 0.000 & 0.000 & 0.823 & 0.889 & 0.578 \\
\hline \multirow[t]{2}{*}{$B U B_{t}^{n}$} & $1796.770^{* * *}$ & $685.030^{* * *}$ & $15.900^{* * *}$ & $5.960^{* *}$ & 0.510 \\
\hline & 0.000 & 0.000 & 0.000 & 0.015 & 0.476 \\
\hline \multirow[t]{2}{*}{$A D B_{t}^{n}$} & $85.260^{* * *}$ & $451.030^{* * *}$ & $202.520^{* * *}$ & $45.570^{* * *}$ & $14.360^{* * *}$ \\
\hline & 0.000 & 0.000 & 0.000 & 0.000 & 0.000 \\
\hline \multirow[t]{2}{*}{$A U B_{t}^{n}$} & $454.940^{* * *}$ & $115.050^{* * *}$ & $78.750^{* * *}$ & $16.640^{* * *}$ & $5.390^{* *}$ \\
\hline & 0.000 & 0.000 & 0.000 & 0.000 & 0.020 \\
\hline
\end{tabular}

Panel A and B in the table reports estimated coefficients and standard errors of the conditional effects model of Section 2.3 using trade-by-trade data. $B D B^{n}$ takes the value 1 before a downward barrier breach, 0 otherwise. $B U B^{n}$ takes the value 1 before an upward barrier breach, 0 otherwise. $A D B^{n}$ takes the value 1 after a downward barrier breach, 0 otherwise. $A U B^{n}$ takes the value 1 after an upward barrier breach, 0 otherwise. $\mathrm{n}$ denotes the reaction window that allows us to assess the market reaction speed between 1-5 subsequent trades $((\mathrm{n}=1,2,3,4$ and 5$)$. Panel A focuses in the Drachma denominated period and the 100s digits, while Panel B repeats for the Euro denominated period and the 1s digits. Panel C presents F-statistics and p-values for the statistical significance tests for the equality of the coefficients between the two period on each occasion. ${ }^{*} p<0.10,{ }^{* *} p<0.05,{ }^{* * *} p<0.01$ 
Table 7: Psychological barriers in equity pricing (stock: OTE)

\begin{tabular}{|c|c|c|c|c|c|c|c|c|c|c|c|c|}
\hline \multirow[b]{2}{*}{ 1998-2000 } & \multicolumn{3}{|c|}{ 100s Drachma } & \multicolumn{3}{|c|}{ 1000s Drachma } & \multicolumn{3}{|l|}{ 1s Euro } & \multicolumn{3}{|l|}{ 10s Euro } \\
\hline & $n=1$ & $n=2$ & $n=5$ & $n=1$ & $n=2$ & $n=5$ & $n=1$ & $n=2$ & $n=5$ & $n=1$ & $n=2$ & $n=5$ \\
\hline \multirow{2}{*}{$R_{t-1}$} & $0.1081^{* *}$ & $0.0949 * *$ & $0.0918^{* *}$ & $0.1172^{* * *}$ & $0.0892^{* *}$ & $0.0842^{* *}$ & $0.1067^{* *}$ & $0.0956^{* *}$ & $0.0892^{* *}$ & $0.1120^{* * *}$ & $0.1032^{* * *}$ & $0.0907^{* *}$ \\
\hline & 0.016 & 0.018 & 0.014 & 0.010 & 0.028 & 0.025 & 0.021 & 0.018 & 0.017 & 0.007 & 0.009 & 0.016 \\
\hline \multirow[t]{2}{*}{$B D B_{t}^{n}$} & 0.0011 & -0.0023 & -0.0013 & -0.0060 & -0.0036 & 0.0006 & -0.0015 & -0.0026 & 0.0015 & $-0.0112^{*}$ & -0.0067 & 0.0013 \\
\hline & 0.840 & 0.531 & 0.829 & 0.123 & 0.259 & 0.855 & 0.690 & 0.434 & 0.757 & 0.069 & 0.148 & 0.713 \\
\hline \multirow[t]{2}{*}{$B U B_{t}^{n}$} & 0.0089 & 0.0004 & 0.0014 & 0.0062 & 0.0004 & 0.0035 & 0.0063 & -0.0010 & -0.0001 & 0.0020 & 0.0010 & -0.0021 \\
\hline & 0.102 & 0.907 & 0.799 & 0.112 & 0.893 & 0.293 & 0.109 & 0.757 & 0.987 & 0.727 & 0.815 & 0.548 \\
\hline \multirow[t]{2}{*}{$A D B_{t}^{n}$} & 0.0080 & 0.0042 & 0.0026 & -0.0017 & -0.0009 & -0.0038 & 0.0001 & 0.0027 & -0.0002 & 0.0064 & 0.0051 & 0.0006 \\
\hline & 0.151 & 0.264 & 0.674 & 0.691 & 0.781 & 0.262 & 0.977 & 0.432 & 0.969 & 0.335 & 0.296 & 0.862 \\
\hline \multirow[t]{2}{*}{$A U B_{t}^{n}$} & 0.0061 & 0.0032 & 0.0010 & -0.0064 & -0.0001 & -0.0020 & -0.0016 & 0.0017 & 0.0002 & -0.0036 & 0.0002 & 0.0002 \\
\hline & 0.272 & 0.373 & 0.865 & 0.134 & 0.988 & 0.551 & 0.704 & 0.624 & 0.962 & 0.554 & 0.970 & 0.961 \\
\hline \multicolumn{13}{|l|}{ 2001-2003 } \\
\hline \multirow[t]{2}{*}{$R_{t-1}$} & -0.0381 & 0.0257 & 0.0395 & 0.0509 & 0.0562 & 0.0441 & 0.0715 & 0.0310 & 0.0400 & 0.0368 & 0.0326 & 0.0441 \\
\hline & 0.542 & 0.575 & 0.305 & 0.207 & 0.155 & 0.252 & 0.145 & 0.467 & 0.302 & 0.330 & 0.389 & 0.238 \\
\hline \multirow[t]{2}{*}{$B D B_{t}^{n}$} & -0.0004 & -0.0003 & 0.0000 & 0.0013 & -0.0008 & -0.0021 & 0.0004 & 0.0018 & 0.0004 & -0.0019 & -0.0068 & $-0.0056^{*}$ \\
\hline & 0.817 & 0.821 & 0.986 & 0.723 & 0.749 & 0.295 & 0.857 & 0.282 & 0.805 & 0.753 & 0.117 & 0.065 \\
\hline \multirow[t]{2}{*}{$B U B_{t}^{n}$} & 0.0015 & 0.0017 & 0.0013 & 0.0001 & 0.0010 & 0.0013 & $0.0053^{* *}$ & $0.0031^{*}$ & 0.0021 & -0.0012 & -0.0018 & -0.0025 \\
\hline & 0.410 & 0.250 & 0.491 & 0.975 & 0.709 & 0.551 & 0.018 & 0.067 & 0.171 & 0.848 & 0.697 & 0.433 \\
\hline \multirow[t]{2}{*}{$A D B_{t}^{n}$} & $-0.0061^{* * *}$ & $-0.0035^{* *}$ & $-0.0038^{*}$ & -0.0019 & -0.0005 & -0.0022 & 0.0005 & -0.0016 & -0.0014 & -0.0040 & -0.0020 & 0.0020 \\
\hline & 0.004 & 0.037 & 0.069 & 0.622 & 0.846 & 0.296 & 0.850 & 0.373 & 0.360 & 0.521 & 0.650 & 0.516 \\
\hline \multirow[t]{2}{*}{$A U B_{t}^{n}$} & -0.0003 & -0.0012 & 0.0005 & 0.0004 & -0.0007 & 0.0012 & -0.0013 & 0.0014 & 0.0018 & $0.0159^{* *}$ & $0.0114^{* *}$ & 0.0043 \\
\hline & 0.895 & 0.479 & 0.812 & 0.924 & 0.816 & 0.595 & 0.607 & 0.445 & 0.245 & 0.013 & 0.014 & 0.182 \\
\hline
\end{tabular}

Table reports estimated coefficients and p-values for Equation 2 using daily closing prices. $B D B^{n}$ takes the value 1 before a downward barrier breach, 0 otherwise, $B U B^{n}$ takes the value 1 before an upward barrier breach, 0 otherwise. $A D B^{n}$ takes the value 1 after a downward barrier breach, 0 otherwise. $A U B^{n}$ takes the value 1 after an upward barrier breach, 0 otherwise. $n$ denotes the reaction window that allows us to assess, in particular, the market reaction speed for 1,2 , and 5 days following a barrier breach. ${ }^{*} p<0.10,{ }^{* *} p<0.05,{ }^{* * *} p<0.01$ 
Table 8: Psychological barriers in equity pricing (stock: NBG)

\begin{tabular}{|c|c|c|c|c|c|c|c|c|c|c|c|c|}
\hline \multirow[b]{2}{*}{$1998-2000$} & \multicolumn{3}{|c|}{ 100s Drachma } & \multicolumn{3}{|c|}{ 1000s Drachma } & \multicolumn{3}{|l|}{ 1s Euro } & \multicolumn{3}{|l|}{ 10s Euro } \\
\hline & $n=1$ & $n=2$ & $n=5$ & $n=1$ & $n=2$ & $n=5$ & $n=1$ & $n=2$ & $n=5$ & $n=1$ & $n=2$ & $n=5$ \\
\hline \multirow{2}{*}{$R_{t-1}$} & -0.0207 & 0.0008 & 0.0203 & -0.0058 & 0.0247 & 0.0160 & -0.0145 & 0.0152 & 0.0156 & 0.0032 & 0.0007 & 0.0004 \\
\hline & 0.758 & 0.986 & 0.619 & 0.894 & 0.563 & 0.691 & 0.788 & 0.751 & 0.705 & 0.938 & 0.986 & 0.992 \\
\hline \multirow[t]{2}{*}{$B D B_{t}^{n}$} & 0.0041 & $0.0052^{* *}$ & $0.0084^{* *}$ & 0.0048 & 0.0062 & 0.0065 & 0.0051 & 0.0021 & $0.0060^{* *}$ & 0.0068 & -0.0223 & -0.0151 \\
\hline & 0.183 & 0.046 & 0.031 & 0.523 & 0.262 & 0.170 & 0.199 & 0.483 & 0.034 & 0.834 & 0.333 & 0.301 \\
\hline \multirow[t]{2}{*}{$B U B_{t}^{n}$} & 0.0034 & 0.0031 & -0.0029 & 0.0005 & 0.0065 & -0.0048 & -0.0014 & -0.0005 & -0.0034 & -0.0018 & 0.0071 & 0.0187 \\
\hline & 0.289 & 0.245 & 0.350 & 0.947 & 0.229 & 0.297 & 0.717 & 0.879 & 0.231 & 0.938 & 0.663 & 0.200 \\
\hline \multirow[t]{2}{*}{$A D B_{t}^{n}$} & -0.0007 & -0.0019 & 0.0029 & 0.0015 & $0.0106^{*}$ & 0.0072 & -0.0015 & 0.0017 & 0.0002 & -0.0064 & -0.0020 & -0.0238 \\
\hline & 0.843 & 0.505 & 0.460 & 0.844 & 0.062 & 0.125 & 0.729 & 0.608 & 0.944 & 0.845 & 0.931 & 0.246 \\
\hline \multirow[t]{2}{*}{$A U B_{t}^{n}$} & 0.0022 & -0.0008 & -0.0035 & 0.0090 & -0.0026 & -0.0038 & 0.0033 & 0.0003 & -0.0044 & 0.0262 & 0.0190 & 0.0164 \\
\hline & 0.608 & 0.790 & 0.256 & 0.244 & 0.642 & 0.423 & 0.486 & 0.921 & 0.131 & 0.264 & 0.251 & 0.115 \\
\hline \multicolumn{13}{|l|}{ 2001-2003 } \\
\hline \multirow[t]{2}{*}{$R_{t-1}$} & -0.0374 & -0.0332 & -0.0112 & -0.0034 & -0.0090 & -0.0187 & 0.0246 & 0.0098 & 0.0048 & 0.0005 & -0.0074 & -0.0055 \\
\hline & 0.486 & 0.449 & 0.770 & 0.928 & 0.812 & 0.617 & 0.557 & 0.805 & 0.901 & 0.990 & 0.840 & 0.880 \\
\hline \multirow[t]{2}{*}{$B D B_{t}^{n}$} & 0.0015 & 0.0020 & 0.0008 & - 0.0103* & -0.0007 & $-0.0051^{*}$ & -0.0024 & 0.0024 & 0.0015 & 0.0258 & $0.0475^{* * *}$ & $0.0360^{* * *}$ \\
\hline & 0.485 & 0.246 & 0.627 & 0.073 & 0.871 & 0.083 & 0.404 & 0.270 & 0.395 & 0.141 & 0.000 & 0.000 \\
\hline \multirow[t]{2}{*}{$B U B_{t}^{n}$} & 0.0023 & 0.0017 & 0.0017 & -0.0003 & 0.0003 & 0.0014 & -0.0023 & 0.0003 & -0.0013 & $0.0275^{*}$ & 0.0074 & $-0.0282^{* * *}$ \\
\hline & 0.307 & 0.337 & 0.325 & 0.964 & 0.938 & 0.675 & 0.441 & 0.908 & 0.497 & 0.069 & 0.497 & 0.008 \\
\hline \multirow[t]{2}{*}{$A D B_{t}^{n}$} & - $0.0047^{*}$ & - $0.0036^{*}$ & -0.0019 & 0.0026 & -0.0022 & -0.0022 & 0.0013 & 0.0008 & 0.0003 & $-0.0278^{* *}$ & -0.0013 & 0.0116 \\
\hline & 0.062 & 0.054 & 0.269 & 0.652 & 0.585 & 0.487 & 0.668 & 0.719 & 0.854 & 0.026 & 0.904 & 0.224 \\
\hline \multirow[t]{2}{*}{$A U B_{t}^{n}$} & - 0.0009 & 0.0007 & 0.0018 & $0.0108^{*}$ & 0.0068 & $0.0085^{* * *}$ & -0.0027 & -0.0011 & -0.0003 & - $0.0516^{* * *}$ & $-0.0582^{* * *}$ & $-0.0320^{* * *}$ \\
\hline & 0.725 & 0.731 & 0.308 & 0.074 & 0.113 & 0.006 & 0.403 & 0.652 & 0.878 & 0.003 & 0.000 & 0.001 \\
\hline
\end{tabular}

Table reports estimated coefficients and p-values for Equation 2 using daily closing prices. $B D B^{n}$ takes the value 1 before a downward barrier breach, 0 otherwise. $B U B^{n}$ takes the value 1 before an upward barrier breach, 0 otherwise. $A D B^{n}$ takes the value 1 after a downward barrier breach, 0 otherwise. $A U B^{n}$ takes the value 1 after an upward barrier breach, 0 otherwise. $n$ denotes the reaction window that allows us to assess, in particular, the market reaction speed for 1,2 , and 5 days following a barrier breach. ${ }^{*} p<0.10,{ }^{* *} p<0.05,{ }^{* * *} p<0.01$ 
Table 9: Psychological barriers in equity pricing (stock: Alpha Bank)

\begin{tabular}{|c|c|c|c|c|c|c|c|c|c|c|c|c|}
\hline \multirow[b]{2}{*}{ 1998-2000 } & \multicolumn{3}{|c|}{ 100s Drachma } & \multicolumn{3}{|c|}{ 1000s Drachma } & \multicolumn{3}{|l|}{ 1s Euro } & \multicolumn{3}{|l|}{ 10s Euro } \\
\hline & $n=1$ & $n=2$ & $n=5$ & $n=1$ & $n=2$ & $n=5$ & $n=1$ & $n=2$ & $n=5$ & $n=1$ & $n=2$ & $n=5$ \\
\hline \multirow[t]{2}{*}{$R_{t-1}$} & -0.0433 & -0.0281 & -0.0188 & -0.0450 & -0.0347 & -0.0258 & -0.0456 & -0.0223 & -0.0187 & -0.0280 & -0.0255 & -0.0208 \\
\hline & 0.284 & 0.464 & 0.613 & 0.271 & 0.366 & 0.492 & 0.266 & 0.562 & 0.614 & 0.480 & 0.511 & 0.579 \\
\hline \multirow[t]{2}{*}{$B D B_{t}^{n}$} & -0.0082 & $-0.0121^{* *}$ & - $0.0130^{*}$ & -0.0049 & $-0.0111^{* *}$ & -0.0029 & -0.0050 & $-0.0090^{* *}$ & -0.0053 & -0.0052 & -0.0038 & 0.0003 \\
\hline & 0.242 & 0.014 & 0.080 & 0.376 & 0.013 & 0.519 & 0.338 & 0.049 & 0.371 & 0.493 & 0.507 & 0.946 \\
\hline \multirow{2}{*}{$B U B_{t}^{n}$} & -0.0037 & -0.0031 & 0.0025 & 0.0008 & 0.0024 & 0.0040 & -0.0013 & -0.0002 & 0.0024 & 0.0093 & $0.0113^{* *}$ & 0.0059 \\
\hline & 0.597 & 0.518 & 0.741 & 0.873 & 0.583 & 0.371 & 0.802 & 0.966 & 0.663 & 0.187 & 0.036 & 0.198 \\
\hline \multirow[t]{2}{*}{$A D B_{t}^{n}$} & -0.0033 & -0.0001 & -0.0040 & -0.0060 & -0.0047 & $-0.0075^{*}$ & -0.0030 & 0.0020 & -0.0037 & 0.0036 & -0.0039 & -0.0048 \\
\hline & 0.646 & 0.985 & 0.599 & 0.289 & 0.305 & 0.097 & 0.584 & 0.669 & 0.538 & 0.652 & 0.512 & 0.314 \\
\hline \multirow[t]{2}{*}{$A U B_{t}^{n}$} & 0.0048 & 0.0053 & 0.0042 & 0.0057 & 0.0058 & 0.0010 & 0.0067 & 0.0061 & 0.0042 & $0.0138^{*}$ & 0.0025 & 0.0032 \\
\hline & 0.501 & 0.279 & 0.574 & 0.301 & 0.196 & 0.836 & 0.221 & 0.187 & 0.448 & 0.056 & 0.658 & 0.491 \\
\hline \multicolumn{13}{|l|}{ 2001-2003 } \\
\hline \multirow[t]{2}{*}{$R_{t-1}$} & 0.0267 & 0.0411 & 0.0549 & $0.1237^{* * *}$ & $0.0998^{* *}$ & $0.0791^{* *}$ & 0.0999 & 0.0550 & 0.0596 & $0.1086^{* * *}$ & $0.0852^{* *}$ & $0.0966^{* * *}$ \\
\hline & 0.659 & 0.363 & 0.163 & 0.004 & 0.015 & 0.040 & 0.051 & 0.211 & 0.127 & 0.005 & 0.025 & 0.010 \\
\hline \multirow[t]{2}{*}{$B D B_{t}^{n}$} & $-0.0032 *$ & -0.0005 & -0.0012 & 0.0028 & -0.0022 & -0.0020 & - $0.0035^{*}$ & $-0.0039^{* *}$ & -0.0019 & 0.0035 & -0.0016 & -0.0040 \\
\hline & 0.084 & 0.782 & 0.600 & 0.374 & 0.361 & 0.288 & 0.097 & 0.019 & 0.247 & 0.529 & 0.698 & 0.195 \\
\hline \multirow[t]{2}{*}{$B U B_{t}^{n}$} & 0.0021 & $0.0033^{*}$ & 0.0020 & -0.0036 & 0.0000 & 0.0002 & -0.0012 & 0.0011 & $0.0031^{* *}$ & -0.0015 & 0.0030 & -0.0000 \\
\hline & 0.279 & 0.053 & 0.298 & 0.294 & 0.996 & 0.911 & 0.577 & 0.508 & 0.050 & 0.811 & 0.510 & 0.999 \\
\hline \multirow[t]{2}{*}{$A D B_{t}^{n}$} & -0.0021 & -0.0021 & $-0.0058^{* *}$ & -0.0001 & -0.0022 & $-0.0034^{*}$ & 0.0035 & -0.0012 & $-0.0034^{* *}$ & 0.0028 & -0.0031 & 0.0006 \\
\hline & 0.339 & 0.260 & 0.013 & 0.980 & 0.384 & 0.081 & 0.152 & 0.495 & 0.047 & 0.631 & 0.460 & 0.843 \\
\hline \multirow[t]{2}{*}{$A U B_{t}^{n}$} & 0.0026 & 0.0023 & 0.0028 & -0.0050 & -0.0032 & 0.0017 & 0.0033 & $0.0034^{*}$ & $0.0029^{*}$ & -0.0034 & 0.0063 & -0.0003 \\
\hline & 0.276 & 0.198 & 0.160 & 0.174 & 0.234 & 0.390 & 0.203 & 0.080 & 0.087 & 0.586 & 0.167 & 0.941 \\
\hline
\end{tabular}

Table reports estimated coefficients and p-values for Equation 2 using daily closing prices. $B D B^{n}$ takes the value 1 before a downward barrier breach, 0 otherwise. $B U B^{n}$ takes the value 1 before an upward barrier breach, 0 otherwise. $A D B^{n}$ takes the value 1 after a downward barrier breach, 0 otherwise. $A U B^{n}$ takes the value 1 after an upward barrier breach, 0 otherwise. $n$ denotes the reaction window that allows us to assess, in particular, the market reaction speed for 1,2 , and 5 days following a barrier breach. ${ }^{*} p<0.10,{ }^{* *} p<0.05,{ }^{* * *} p<0.01$ 
Table 10: Psychological barriers in equity pricing (stock: HelPe)

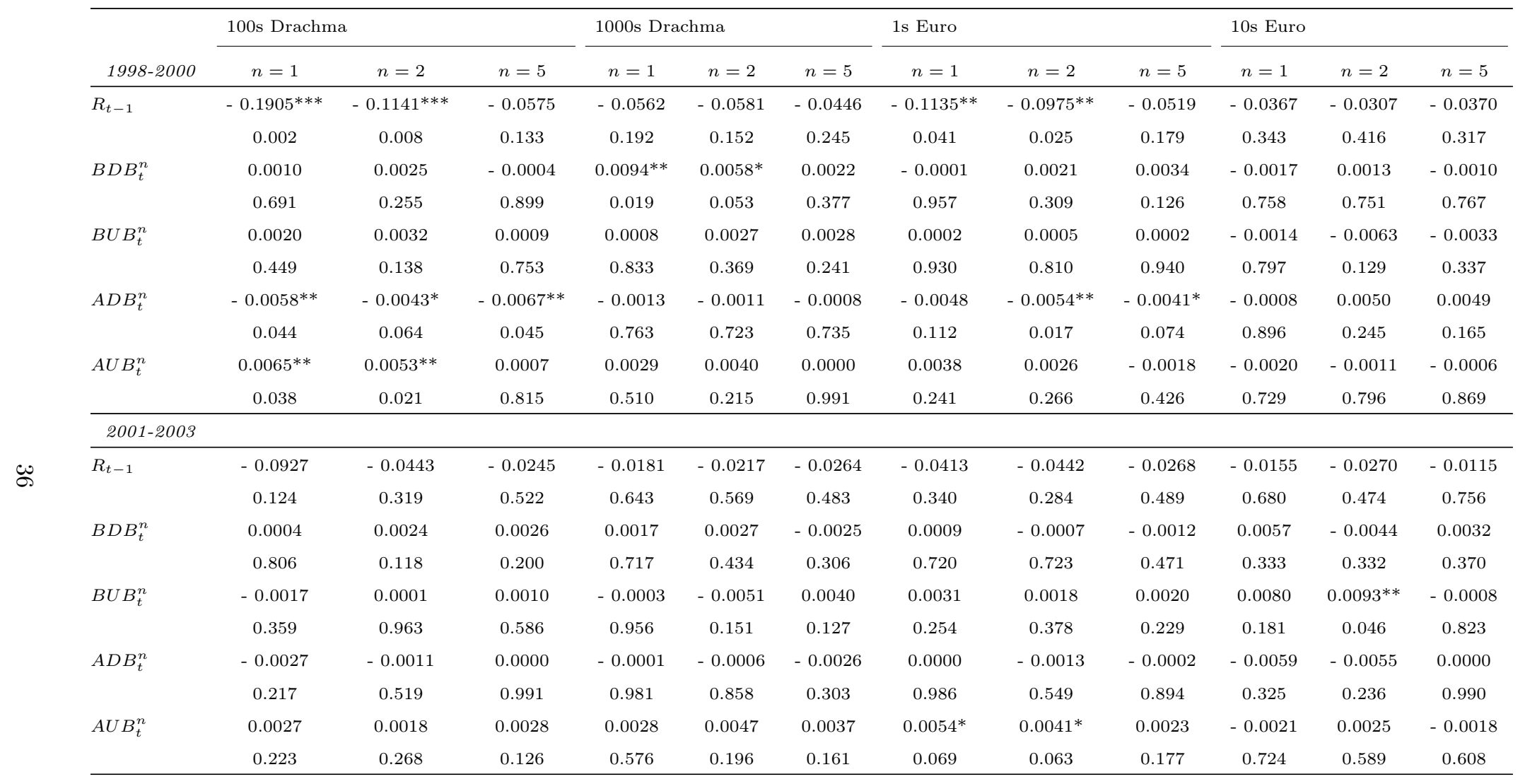

Table reports estimated coefficients and p-values for Equation 2 using daily closing prices. $B D B^{n}$ takes the value 1 before a downward barrier breach, 0 otherwise. $B U B^{n}$ takes the value 1 before an upward barrier breach, 0 otherwise. $A D B^{n}$ takes the value 1 after a downward barrier breach, 0 otherwise. $A U B^{n}$ takes the value 1 after an upward barrier breach, 0 otherwise. $n$ denotes the reaction window that allows us to assess, in particular, the market reaction speed for 1,2 , and 5 days following a barrier breach. ${ }^{*} p<0.10,{ }^{* *} p<0.05,{ }^{* * *} p<0.01$ 
Table 11: Psychological barriers in equity pricing (stock: Vodafone)

\begin{tabular}{|c|c|c|c|c|c|c|c|c|c|c|c|c|}
\hline \multirow[b]{2}{*}{ 1998-2000 } & \multicolumn{3}{|c|}{ 100s Drachma } & \multicolumn{3}{|c|}{ 1000s Drachma } & \multicolumn{3}{|l|}{ 1s Euro } & \multicolumn{3}{|l|}{ 10s Euro } \\
\hline & $n=1$ & $n=2$ & $n=5$ & $n=1$ & $n=2$ & $n=5$ & $n=1$ & $n=2$ & $n=5$ & $n=1$ & $n=2$ & $n=5$ \\
\hline \multirow[t]{2}{*}{$R_{t-1}$} & 0.0268 & 0.0293 & 0.0145 & 0.0162 & 0.0560 & 0.0273 & 0.0063 & 0.0461 & 0.0203 & - 0.0019 & -0.0014 & 0.0074 \\
\hline & 0.630 & 0.541 & 0.747 & 0.740 & 0.237 & 0.543 & 0.908 & 0.348 & 0.654 & 0.970 & 0.977 & 0.871 \\
\hline \multirow[t]{2}{*}{$B D B_{t}^{n}$} & -0.0042 & -0.0022 & 0.0002 & 0.0037 & -0.0072 & 0.0026 & 0.0014 & -0.0020 & 0.0017 & -0.0034 & 0.0232 & 0.0195 \\
\hline & 0.387 & 0.624 & 0.973 & 0.611 & 0.190 & 0.555 & 0.791 & 0.633 & 0.683 & 0.905 & 0.219 & 0.111 \\
\hline \multirow[t]{2}{*}{$B U B_{t}^{n}$} & 0.0027 & 0.0009 & -0.0042 & 0.0050 & 0.0031 & -0.0058 & 0.0041 & 0.0029 & -0.0027 & 0.0141 & 0.0290 & 0.0154 \\
\hline & 0.590 & 0.831 & 0.410 & 0.499 & 0.571 & 0.197 & 0.432 & 0.494 & 0.510 & 0.659 & 0.201 & 0.324 \\
\hline \multirow[t]{2}{*}{$A D B_{t}^{n}$} & 0.0021 & 0.0045 & -0.0054 & 0.0037 & 0.0077 & 0.0044 & 0.0033 & 0.0045 & 0.0013 & -0.0189 & -0.0122 & -0.0026 \\
\hline & 0.688 & 0.323 & 0.408 & 0.624 & 0.174 & 0.332 & 0.561 & 0.303 & 0.763 & 0.522 & 0.535 & 0.834 \\
\hline \multirow[t]{2}{*}{$A U B_{t}^{n}$} & 0.0003 & 0.0011 & -0.0050 & 0.0053 & $-0.0143^{* *}$ & - 0.0119*** & 0.0055 & -0.0043 & -0.0027 & 0.0255 & -0.0074 & -0.0044 \\
\hline & 0.951 & 0.798 & 0.331 & 0.490 & 0.014 & 0.008 & 0.354 & 0.342 & 0.516 & 0.467 & 0.749 & 0.765 \\
\hline \multicolumn{13}{|l|}{ 2001-2003 } \\
\hline \multirow[t]{2}{*}{$R_{t-1}$} & -0.0084 & -0.0555 & -0.0507 & -0.0204 & -0.0285 & -0.0205 & -0.0264 & -0.0413 & -0.0300 & & & \\
\hline & 0.865 & 0.187 & 0.192 & 0.592 & 0.446 & 0.580 & 0.507 & 0.287 & 0.425 & & & \\
\hline \multirow[t]{2}{*}{$B D B_{t}^{n}$} & 0.0017 & 0.0027 & -0.0003 & 0.0038 & 0.0036 & 0.0029 & -0.0004 & -0.0011 & -0.0001 & & & \\
\hline & 0.477 & 0.131 & 0.859 & 0.405 & 0.285 & 0.267 & 0.917 & 0.702 & 0.969 & & & \\
\hline \multirow[t]{2}{*}{$B U B_{t}^{n}$} & 0.0005 & 0.0011 & 0.0009 & -0.0006 & 0.0024 & -0.0012 & -0.0002 & 0.0034 & 0.0015 & & & \\
\hline & 0.829 & 0.552 & 0.581 & 0.892 & 0.469 & 0.676 & 0.968 & 0.234 & 0.484 & & & \\
\hline \multirow[t]{2}{*}{$A D B_{t}^{n}$} & 0.0024 & -0.0010 & -0.0019 & 0.0048 & 0.0004 & 0.0030 & -0.0001 & -0.0029 & -0.0014 & & & \\
\hline & 0.378 & 0.597 & 0.236 & 0.300 & 0.917 & 0.272 & 0.987 & 0.311 & 0.503 & & & \\
\hline \multirow[t]{2}{*}{$A U B_{t}^{n}$} & -0.0002 & 0.0028 & 0.0026 & -0.0001 & -0.0003 & -0.0029 & -0.0002 & 0.0017 & -0.0009 & & & \\
\hline & 0.940 & 0.147 & 0.112 & 0.980 & 0.938 & 0.293 & 0.968 & 0.552 & 0.678 & & & \\
\hline
\end{tabular}

Table reports estimated coefficients and p-values for Equation 2 using daily closing prices. $B D B^{n}$ takes the value 1 before a downward barrier breach, 0 otherwise, $B U B^{n}$ takes the value 1 before an upward barrier breach, 0 otherwise, $A D B^{n}$ takes the value 1 after a downward barrier breach, 0 otherwise. $A U B^{n}$ takes the value 1 after an upward barrier breach, 0 otherwise. $n$ denotes the reaction window that allows us to assess, in particular, the market reaction speed for 1,2 , and 5 days following a barrier breach. Note: for Vodafone there are no relevant $€ 10$ barrier points during the euro period. ${ }^{*} p<0.10,{ }^{* *} p<0.05,{ }^{* * *} p<0.01$ 